\title{
Mercury Pollution from Dental Amalgam Waste in Trinidad and Tobago
}

\author{
Amit Paryag ${ }^{1}$, Amrita S. Paryage ${ }^{2}$, Reisha N. Rafeek ${ }^{1}$, Angelus Pilgrim² \\ ${ }^{1}$ School of Dentistry, University of the West Indies, St. Augustine, Trinidad and Tobago \\ ${ }^{2}$ Faculty of Engineering University of the West Indies, St. Augustine, Trinidad and Tobago \\ E-mail: reisha.rafeek@sta.uwi.edu \\ Received January 25, 2010; revised March 22, 2010; accepted April 10, 2010
}

\begin{abstract}
Aim: To assess the knowledge and attitudes of dental practitioners regarding the disposal of amalgam waste from dental practices and to assess the level of mercury released via dental amalgam waste into the environment in Trinidad and Tobago. Method: A questionnaire on dental wastewater discharge and amalgam waste disposal was administered to dental practitioners in Trinidad and Tobago. Levels of mercury in samples of wastewater and solid deposits obtained during removal of 160 amalgam fillings, were measured using Atomic Absorption Spectrometry. The numbers of amalgam fillings placed and removed over a monthly period from a random sample of dental practices in Trinidad and Tobago were also obtained via the questionnaires. The amount of mercury entering the environment from dental practices was estimated from these data. Results: Twenty per cent responded to the questionnaire. Thirty per cent of respondents used elemental mercury (from a dispenser), while $74.4 \%$ used pre-capsulated mercury for preparing amalgam fillings. Seventy nine per cent used chair-side traps and filters but none had amalgam separators in their surgery. Methods used to dispose of amalgam waste included disposal in the trash (48.8\%), washing down the sink (39.5\%); and as hazardous waste (37.2\%). A mean concentration of $0.0759 \mathrm{ppm}(\mathrm{or} \mathrm{mg} / \mathrm{L})$ mercury was found in filtrate from the wastewater samples. A total concentration of $3.4 \mathrm{~g}$ mercury per dentist per day was found to be released into the environment via dental amalgam waste in Trinidad and Tobago. Conclusion: Best management practices for disposal of dental amalgam waste are not generally followed. At 3.4 gms per day per dentist, the level of mercury released via dental amalgam waste into the environment in Trinidad and Tobago may be too high. Dental practitioners require education on the management of dental amalgam waste and national legislation to protect the environment from this source of mercury may be required.
\end{abstract}

Keywords: Dental Amalgam, Mercury Pollution

\section{Introduction}

An amalgam is an alloy of Mercury and one or more other metals. The amalgam alloy is a combination of solid metals containing mainly particles of silver, tin and copper [1]. Other particles, which are sometimes included, are zinc, palladium, indium and selenium. Dental amalgam is made by mixing liquid mercury with powdered amalgam alloys in a process called "trituration". Trituration of commercial amalgam alloys produces a plastic mass (the "amalgam") that the dentist places in a cavity preparation [2].

Mercury occurs naturally in the environment and exists in several forms. It may change between different states and species in its cycle, but its simplest form is elemental mercury, which itself is harmful to humans and the environment. Once mercury has been brought into circulation in the biosphere by human activity it does not disappear again in time spans comparable to human lifetime [3].When compared with industrial pollution and combustion of fossil fuels by vehicles, the mercury contained in dental amalgams is not a major source of mercury release to the environment, (globally, approximately 10,000 tons of mercury are mined each year, with an estimated 3-4\% used in dentistry [4]. However, its environmental impact is mainly due to the poor management of dental amalgam waste.

During the 1970s and 1980s, 50\% of the mercury used in dental practices was discharged into the environment: $20 \%$ of this was lost to the air and $30 \%$ to the sewage 
system. During this period 5.6 tonnes of mercury per year were discharged into UK sewers. Furthermore, only $5 \%$ of the dental practices surveyed used amalgam separator in their waste disposal system [5]. Previous studies have established the level of mercury in the filtrate from wastewater discharged during amalgam removal to be approximately $0.1493 \mathrm{ppm}$ (or mg/l) when no amalgam separator is used [6]. The total estimated release in one study was $1.196 \mathrm{~g} /$ day/dentist [7].

Evacuation systems in existing dental practices typically contain either one or two components that are capable of removing solids such as amalgam particles from wastewater-chairside traps and vacuum pump filters. Chairside traps are commonly used in both wet and dry vacuum systems. They remove particles down to approximately $0.7 \mathrm{~mm}$. In addition to chairside traps, systems with a wet vacuum pump typically have a filter located just upstream of the pump that is designed to protect the pump from large solids. Vacuum pump filters have pore sizes of either $0.84 \mathrm{~mm}$ (20 mesh screen) or $0.42 \mathrm{~mm}$ (40 mesh screen). Chairside traps and vacuum pump filters successfully remove anywhere from $40-80 \%$ of the total mass of amalgam particles from dental office wastewater, leaving 20-60\% to be discharged to sewers and septic systems [8].

Use of disinfectants containing oxidizing substances in dental aspirator kits may contribute to remobilization of mercury and its subsequent release into the environment [4] In addition, municipal wastewater treatment systems are not designed to treat hazardous waste or reduce mercury loadings to the environment. Consequently, all mercury in the influent wastewater remains unattenuated in municipal treatment plants, and either settles out in the grit chamber or residuals (sludge, or "biosolids"), or passes through the system to be discharged into a downstream lake, river or ocean along with the "treated" effluent. This discharge of mercury directly in the sewer system may greatly increases the possibility for the formation of the more bio-available organic mercury compounds.

In Trinidad and Tobago, no extensive research been conducted into the effect of mercury on our environment and people and no previous research has been done to estimate levels of mercury output from dental practices. There are currently over 235 registered dentists practicing the country and the Dental Association acknowledges that there are hundreds more unregistered persons who practice dentistry. Many of these practices and practitioners still use dental amalgam. At present no definitive legislation exists to regulate the use or disposal of dental amalgam in this country nor is there a company that deals with the disposal of collected amalgam waste. As such it is usually kept under water in a jar and then disposed of along with normal waste.

The objective of this study was to assess the knowledge and attitudes of dental practitioners regarding the disposal of amalgam waste from dental practices and to assess the level of mercury released via dental amalgam waste into the environment in Trinidad and Tobago.

\section{Methods}

\section{Part 1-Questionnaire}

A questionnaire discussing dental wastewater discharge, disposal of amalgam waste and use of filters and separators in dental chairs, was compiled and sent to dentists on the Dental Register in Trinidad and Tobago. The questionnaire also included questions on the number of amalgam fillings (restorations) removed on a monthly basis and the sizes of the fillings.

In order to obtain the level of mercury released via dental amalgam waste, an experiment had to be conducted utilising a typical dental chair unit as described in Part II. The percentage of amalgam entering the sewer system from the removal of dental amalgam from different sizes of fillings as well as the concentration of mercury in the wastewater entering the sewer system was calculated.

The data obtained was used to estimate the quantity of dental amalgam and potentially, the quantity of mercury released from dental practices into the environment. This was done by correlating experimental data from Part II with data collected via the questionnaire regarding the amount of amalgam fillings removed over a monthly period by dentists in Trinidad \& Tobago.

Part 2-The aims of this part of the study were to determine the percentage of amalgam retained in solids separators and the amount lost to the sewerage system during the removal of dental amalgams, as well as to determine the concentration of mercury in the wastewater that enters the sewer system.

The collection of wastewater samples from a typical dental chair unit in a clinical environment and analysis of the amount of mercury present using Atomic Absorption Spectrometry were done by the following steps:

1) Anatomical replica teeth were prepared for and restored with 1, 2, 3 and 4 surface amalgam restorations. They were divided into four (4) groups each consisting of $n=40$ and allowed to set for a period of 48 hours.

2) Before removal of restorations from each set of teeth, the dental unit was thoroughly flushed with water, and this sample collected was used as a blank. All restorations were removed with a Tungsten Carbide High Speed, bur in a water-cooled Star 430K high-speed handpiece (Star Dental, Lancaster, Philadelphia) attached to a dental unit with conventional suction system, in a procedure that mimicked normal operatory conditions. The suction line leading to the vacuum pump was interrupted and attached to a surgical collection unit. This ensured 
that all particles in the suction line (liquid and solid) were collected prior to reaching the vacuum pump, and the public wastewater system. No hand instruments were used to pry restorations from cavities, and care was taken to avoid removing tooth material with the bur.

3) All of the wastewater from each set was collected in $500 \mathrm{ml}$ Nalgene containers. After the restorations had been removed from each set of teeth, the screen (pore size $1.0 \mathrm{~mm}$ ) in the conventional chairside solids separator was removed and the particles of amalgam trapped were collected.

4) Calculations for dilution and digestion of the liquid portion of each sample were performed. (Table 1). Mercury was analyzed on the Varian 600 Atomic Absorption Spectrophotometer, using the VGA-77 vapor generating accessory (Varian Canada Inc., Mississauga, Ontario). The detection limit for these measurements was $0.0001 \mu \mathrm{g} / \mathrm{l}$ (Picture 16). Standards were prepared from certified $1000 \mu \mathrm{g} / \mathrm{ml}$ Mercury Stock Solution (Item Number AA34N-5) obtained from AccuStandard Inc., New Haven, USA.
5) Calculations for dilution and digestion of the solid portion of each sample were performed (Table 1). Approximately $0.1 \mathrm{~g}$ of each of the solid portions of the sample was weighed (Mettler-Toledo AG204 Analytical Balance, Switzerland, to a precision of $0.1 \mathrm{mg}$ ) and digested with 5\% Nitric Acid for about 30 minutes, at $70^{\circ} \mathrm{C}$. The resulting mixture was then quantitatively transferred to a $200 \mathrm{ml}$ volumetric flask and then diluted with deionised water accordingly.

6) The concentration of mercury in each samples (1 surface, 2 surface, 3 surface and 4 surface) for both liquid and solid portions were obtained.

\section{Results}

Responses were obtained from $20 \%$ of the practitioners to the questionnaire discussing dental wastewater discharge and amalgam waste disposal. Over $80 \%$ of the respondents were from privately owned dental practices, whereas $18.6 \%$ were from public health centers and nearly $75 \%$ of the dentists were members of the Dental

Table 1. Calculations to show how dilution factors were determined.

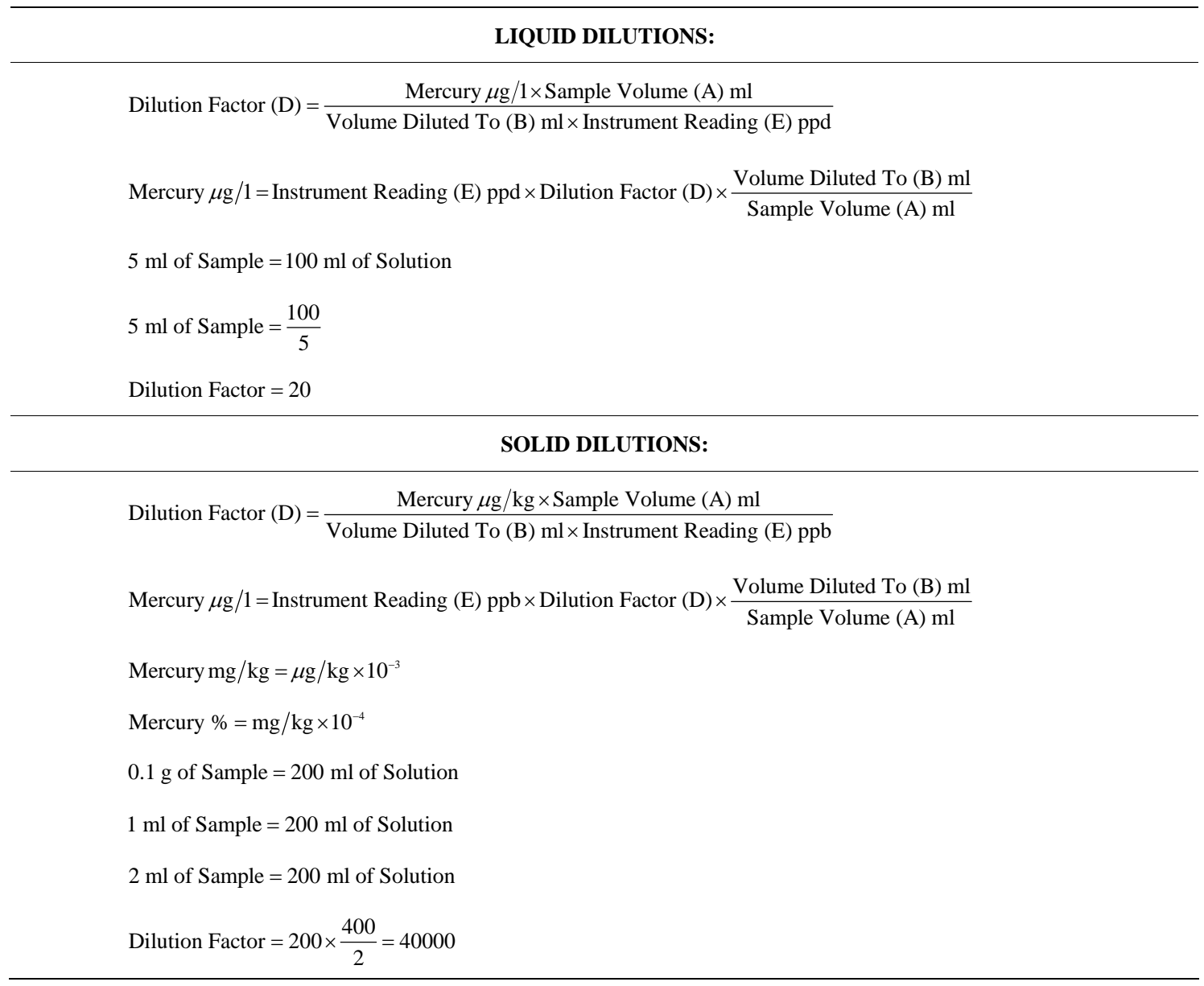


Association. Some of the relevant information regarding the chairside traps, secondary filters and amalgam separators from the questionnaire is outlined in Table 2. 14\% of the dentists used disposable chair side trap filters, while $86 \%$ used reusable chair side trap filters. The frequency with which they cleaned the traps varied as follows: daily (72.1\%); weekly (25.6\%); and monthly (2.3\%).

They managed the waste from the chair side traps by: Recycling (4.7\%); Washing down the sink (39.5\%); Disposal in Trash (48.8\%); Treating as Infectious (Biohazard) waste (32.6\%); and as Hazardous waste (37.2\%). The percentages do not add to $100 \%$ as they could have responded to more than one option. The responses of registered Dental Practitioners to the question of the method of disposal of amalgam waste from chairside traps are represented in Figure 1.

It was also interesting to note that $74.4 \%$ of respondents to the questionnaire used pre-capsulated mercury, 79.1\% used chair side trap filters and 0\% had amalgam separators in their surgery. The extracted teeth with mercury amalgam fillings were disposed of as follows: 9.3\% claimed they placed it in a container for pick up by an amalgam recycler; $20.9 \%$ placed it in a red bag for disposal as medical waste; while $74.4 \%$ placed it in the trash. Information regarding disposal of extracted teeth, non-contact amalgam mixing scrap, empty amalgam capsules, chairside screens, under-sink traps and vacuum filters or screens obtained from the questionnaire is outlined in Table 3. It is noteworthy that in all instances the majority of practitioners dispose of amalgam waste in the trash. The data also revealed the average number of amalgam fillings removed per month by dentists who responded was 29.4.

For 1 Surface restorations, $19.95 \%$ of the total weight of the amalgam restoration removed from teeth was captured by the conventional chairside trap, whereas $80.05 \%$ of the total weight was not recovered. For 2 Surface teeth,
Table 2. Information concerning amalgam waste collection.

\begin{tabular}{lcc}
\hline Use of chairside trap filters & $\begin{array}{c}\text { Disposable trap filters } \\
\text { Reusable trap filters }\end{array}$ & $\begin{array}{c}14 \% \\
\end{array}$ \\
\hline Frequency of cleaning traps & Daily & $72.1 \%$ \\
\hline Use of a secondary filter & Weekly & $25.6 \%$ \\
\hline Possess amalgam separator & Monthly & $2.3 \%$ \\
\hline
\end{tabular}

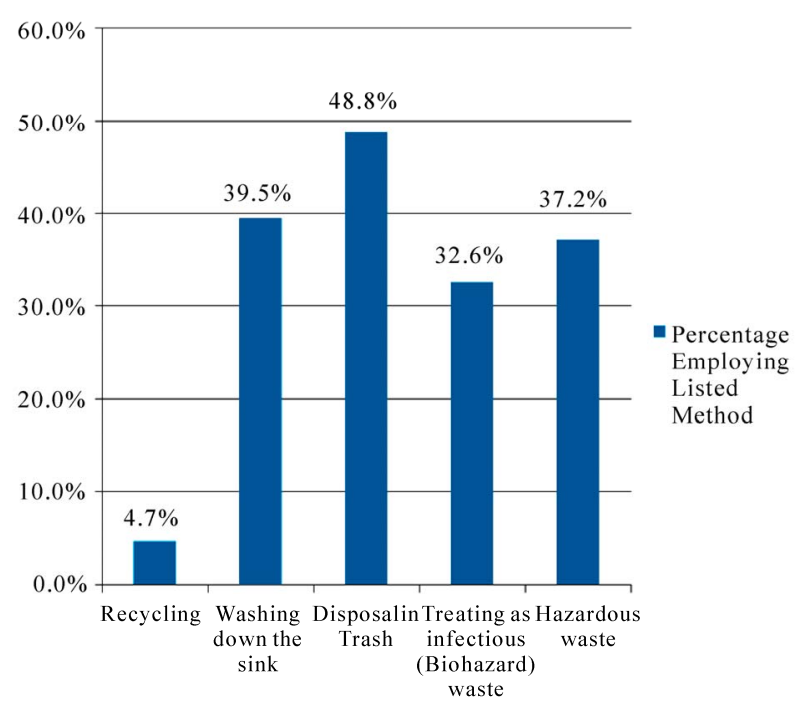

Figure 1. Methods used to dispose of amalgam from chairside traps.

Table 3. Information concerning amalgam waste disposal.

\begin{tabular}{|c|c|c|c|c|}
\hline & $\begin{array}{l}\text { Placed in a container for pick } \\
\text { up by an amalgam recycler }\end{array}$ & $\begin{array}{l}\text { Placed in a red bag for } \\
\text { disposal a medical waste }\end{array}$ & Placed in the trash & Placed in the sink \\
\hline $\begin{array}{l}\text { Disposal of extracted teeth with } \\
\text { amalgam fillings }\end{array}$ & $9.3 \%$ & $20.9 \%$ & $74.4 \%$ & $0 \%$ \\
\hline $\begin{array}{l}\text { Disposal of non contact amalgam } \\
\text { mixing scrap }\end{array}$ & $32.6 \%$ & $23.3 \%$ & $37.2 \%$ & $2.3 \%$ \\
\hline Disposal of empty amalgam capsules & $2.3 \%$ & $16.3 \%$ & $67.4 \%$ & $0 \%$ \\
\hline $\begin{array}{l}\text { Disposal of amalgam waste from } \\
\text { chairside traps }\end{array}$ & $14.0 \%$ & $18.6 \%$ & $51.2 \%$ & $4.7 \%$ \\
\hline $\begin{array}{l}\text { Disposal of amalgam waste from } \\
\text { under sink traps }\end{array}$ & $11.6 \%$ & $20.9 \%$ & $48.8 \%$ & $2.3 \%$ \\
\hline $\begin{array}{l}\text { Disposal of amalgam waste from } \\
\text { vacuum filters }\end{array}$ & $7.0 \%$ & $18.6 \%$ & $51.2 \%$ & $2.3 \%$ \\
\hline
\end{tabular}


$18.60 \%$ of the total weight of the amalgam restoration removed from teeth was captured by the conventional chairside trap, whereas $81.40 \%$ of the total weight was not recovered. For 3 Surface teeth, $12.81 \%$ of the total weight of the amalgam restoration removed from teeth was captured by the conventional chairside trap, whereas $87.19 \%$ of the total weight was not recovered. For 4 Surface restorations, $31.27 \%$ of the total weight of the amalgam restoration removed from teeth was captured by the conventional chairside trap, whereas $68.73 \%$ of the total weight was not recovered.

Therefore only $13 \%-30 \%$ of the weight of restorations removed, were recovered in the primary chairside trap and the bulk of the waste generated (70\%-87\%) was contained in the dental effluent waste.

On average, the concentrations of mercury in the liquid portion (filtrate) of the samples were highest in 4 Surface (0.1087 ppm (or mg/l)), followed by 2 Surface (0.0987 ppm (or mg/l)), 3 Surface (0.0697 ppm (or mg/l)) and 1 Surface $(0.0266 \mathrm{ppm}$ (or $\mathrm{mg} / \mathrm{l})$. The mean concentration of mercury in the liquid portion of all 4 sets of restorations combined (40 teeth) was $0.0758917 \mathrm{ppm}$. Table 4 shows the results for the mean concentration of mercury in the filtrate of the various sizes of restorations removed chairside as well as the overall mean concentration of mercury in the filtrate.

The mean concentrations of mercury in the solid portion of the samples were highest in Surface 2 followed by Surface 3, Surface 1 and Surface 4 . The mean concentration of mercury in the solid portion of all 4 sets of restorations combined (40 teeth) was $4077744.885 \mathrm{ppm}$ (see Table 5).

Using the values obtained from chairside testing for mercury concentration in the liquid filtrate and solid portions as well as data from the dental wastewater discharge questionnaire, the total mercury discharge into the environment from removal of dental amalgam restorations was estimated (Table 6). The combined concentration of mercury released by all dentists in Trinidad and Tobago, on a monthly basis was $22285.35 \mathrm{~g} / \mathrm{month}$. It was estimated that the combined concentration of mercury from both solid and liquid portions released from

Table 4. Mean concentration of mercury in filtrate from samples.

\begin{tabular}{cc}
\hline $\begin{array}{c}\text { No. Of Restored Tooth } \\
\text { Surfaces }\end{array}$ & $\begin{array}{r}\text { Mean Concentration of Mercury In } \\
\text { Filtrate ppm (or mg/l) }\end{array}$ \\
I & 0.0266 \\
II & 0.0987 \\
III & 0.0697 \\
IV & 0.1087 \\
Mean concentration of mercury in filtrate $=0.0759 \mathrm{ppm}$ \\
\hline
\end{tabular}

Table 5. Mean concentration of mercury in amalgam deposits from samples.

\begin{tabular}{cc}
\hline No. Of Restored Tooth Surfaces & $\begin{array}{c}\text { SOLID DEPOSITS } \\
\text { CONCENTRATION (ppm) }\end{array}$ \\
\hline 1-SURFACE & 3705180.702 \\
2-SURFACE & 4848732.847 \\
3-SURFACE & 4690376.106 \\
4-SURFACE & 3066689.882 \\
MEAN CONCENTRATION & 4077744.885 \\
\hline
\end{tabular}

Table 6. Estimated average mercury discharge from amalgam restoration removal.

\begin{tabular}{lc}
\hline $\begin{array}{l}\text { Estimated Average Combined Concentration } \\
\text { of Mercury For All Dentists for } 1 \text { month }\end{array}$ & $22285.35 \mathrm{~g} / \mathrm{month}$ \\
\hline $\begin{array}{l}\text { Estimated Average Combined Concentration } \\
\text { of Mercury per Dentist per month }\end{array}$ & $94.82 \mathrm{~g} / \mathrm{month}$ \\
\hline $\begin{array}{l}\text { Estimated Average Combined Concentration } \\
\text { of Mercury per Dentist per day }\end{array}$ & $3.4 \mathrm{~g} / \mathrm{day}$ \\
\hline
\end{tabular}

the removal of dental amalgam was $3.4 \mathrm{~g}$ per dentist per day.

\section{Discussion}

Dental amalgam, in widespread use for over 150 years, is one of the oldest materials in oral health care. Dentists in the United States placed about 71 million amalgam restorations in 1999 [9]. The history of the controversy surrounding amalgam use is well documented [10]. Whereas the debate on the health effects of amalgam use is well highlighted, the possible impact of mercury from dental amalgam entering the environment has received much less attention. Though Dental Amalgam is a highly favoured restorative material, there is controversy mainly because of human health and environmental concerns.

All dentists on the dental register in Trinidad and Tobago were sent questionnaires however the response rate in this study was approximately $20 \%$, which is low but comparable to other studies with $12 \%$ [11] and 28\% [12]. Also as the dentists were asked to estimate the number of amalgam restorations removed monthly the possibility of recall bias may have occurred.

A study found that more than three-quarters of King County, Washington, dental offices did not reclaim or sequester mercury bearing waste captured in chair side traps or pump filters [13]. Rather, they put it in the garbage, mixed it with medical waste, stored it onsite or put down the drain. These findings were similar in this study with the majority of dental offices placing the waste from 
the traps and filters into the trash or washing it down the sink.

There is enormous variation in the size and shape of waste amalgam debris. The bulk portions are irregularly shaped pieces of amalgam that break away during the process of removing the amalgam restoration from the tooth. They may be up to several millimetres at the widest dimension. Small particles produced from contact with burs operated by an air turbine hand-piece take the form of chips and filings varying in size from a few microns to sub-micron dimensions. Normally, water, saliva, and waste amalgam are removed from the operating site and oral cavity by means of high volume suction.

The bulk portions are relatively easy to capture in the chair-side solids separator (primary trap) because of their substantial size. Virtually all the particles of micron and sub-micron dimensions produced by contact with the bur pass through the primary trap and enter the secondary solids separator (secondary trap) associated with the vacuum pump. Here some settle to the bottom of the trap, but turbulence of water passing through the trap carries the remainder into the waste stream [14].

In part II of the study, samples of wastewater were collected from the discharge pipe, which had been completely disconnected from the drain, during the removal of dental amalgam restorations. This method of sample collection minimizes opportunities for particles to settle out of suspension in the wastewater stream as will occur if a sampling valve is inserted into a wastewater line downstream from the pump. Also, if only a part of the wastewater is collected through a sampling valve the amount of particles in the discharged wastewater will not be accurate because particles of amalgam are not distributed uniformly in the wastewater stream. Furthermore, if the vacuum system is shut down while a sample is taken many particles of amalgam will settle out of suspension. Therefore, this sampling technique ensured that not only dissolved mercury was obtained, but also all the particles of amalgam in the wastewater. A high volume vacuum pump system that requires a continuous flow of water to maintain a seal with the impeller and maintain vacuum was also used.

In order to conserve water some pumps re-circulate a percentage of the water used to maintain the seal. However, the basic principle of operation and solids collection is similar between different brands of these pumps. Still, our ability to recover $31 \%$ or less as solid waste in solids separators may be biased because only one high volume vacuum pump system was used in this study. A lower or higher rate of water consumption by different brands of pumps, or by different water flow adjustments, may influence the concentration of amalgam particles and dissolved mercury as a consequence of the dilution factor.

A higher concentration of mercury was found in the amalgam deposits from the wastewater (the effluent), whereas only a relatively minute quantity of the mercury was dissolved in solution (filtrate from the wastewater samples). This was because of the differences in the dilution factors; the dilution factor for the liquid portion of the samples was $=20$, whereas the dilution factor for the solid portion of the samples was $=40000$. Hence there were more particles of mercury per individual solid sample, as there were per individual liquid sample. In this experiment the wastewater contained about $70 \%$ to $87 \%$ by weight of the waste generated during the removal of amalgam restorations. This is consistent with previous research that reported that less than $0.3 \%$ of amalgam waste is soluble [4].

Previous studies have shown a wide variation in the level of mercury in the filtrate from wastewater discharged during amalgam removal, from $0.1493 \mathrm{mg} / \mathrm{l}$ (ppm) when no amalgam separator is used [6] to 9.7-306 $\mathrm{mg} / \mathrm{l}$ (ppm) [15].This study found the level of concentration of mercury in the filtrate to be $0.0759 \mathrm{mg} / \mathrm{l}(\mathrm{ppm})$ without the use of an amalgam separator. Since these were experiments, the high range is expected because of the large number of variables associated with experimentation. A fraction of particles would have also been lost in the patient's mouth and the operating environment during the removal of restorations

The estimated release of mercury in dental amalgam has been previously reported to be $1.196 \mathrm{~g} /$ day/dentist [7], $250 \mathrm{mg}$ of mercury/day/dentist [16] and $0.46 \mathrm{~g}-271 \mathrm{~g}$ daily per dentist [17]. In Canada, other studies have estimated release of $125 \mathrm{mg}$ per dentist per day of mercury into waste water annually [18], $131 \mathrm{mg} /$ dentist/day [19] and $172.7 \mathrm{mg}$ per dentist/day in Ontario if no amalgam separators were used [20]. The current study estimated the release of mercury from dental amalgam to be 3.4 g/day/dentist.

Zero percent $(0 \%)$ of the dentists reported using any amalgam separating device. The use of ISO-certified amalgam particle separators by all dentists could dramatically reduce dentistry's share of mercury in Trinidad and Tobago's municipal sewage treatment plants. If the amalgam waste generated is not captured before it leaves the dental surgery, it will enter the wastewater system, the sewers and eventually the rivers and oceans. If it is captured but improperly disposed of, it poses an environmental hazard particularly because of the mercury content.

Although lower levels of mercury were found in the filtrate in our study, significantly higher overall levels were estimated as being released into the environment. This may be due to the fact that in estimating the total mercury release the amount of mercury in the amalgam solids in the chairside trap as well as the waste water stream were combined. Additionally, amalgam is still a highly favored restorative material in Trinidad and Tobago. This means that with more amalgam being used and $0 \%$ of dentists using amalgam separators, higher 
levels of mercury may be entering the environment via the wastewater stream. Also with no company possessing the capability of recycling waste amalgam in the country, any amalgam collected either via separators or chairside filters and traps will eventually enter the environment either via landfills or incineration.

Mercury levels in our marine environment are elevated $[21,22]$. No prior work existed to determine how significant a contributor dental amalgam is to these levels. In Trinidad and Tobago, failure to enact the Water Pollution Rules and the Air Pollution Rules along with other pieces of important environmental legislation, has proven to be a hurdle in the regulation of dental amalgam waste.

The current situation however means that this country is ideally positioned for an in depth amalgam waste disposal policy to be properly formulated and implemented in conjunction with appropriate education of practitioners and their staff on the need for careful management of dental amalgam wastes. This research may therefore pave the way for future detailed testing as well as the design and implementation of appropriate policy in Trinidad and Tobago.

\section{Conclusions}

Although dental practitioners in Trinidad and Tobago may have some information about methods of disposal of amalgam waste, education on these methods is required. In addition, best management practices though easy to implement are not often followed. At 3.4 g/day/dentist the level of mercury released via dental amalgam waste into the environment in Trinidad and Tobago may be too high. Separators in dental practices and the incorporation of a company to effectively recycle or process collected waste amalgam, may help control the discharge of amalgam into the wastewater stream.

\section{References}

[1] J. M. Powers and R. L. Sakaguchi, “Craig's Restorative Dental Materials,” 12th Edition, Mosby, St.Louis, 2006.

[2] T. Okabe and R. J. Mitchell, "Setting Reactions in Dental Amalgam, Part 2-The Kinetics of Amalgamation," Critical Reviews in Oral Biology and Medicine, Vol. 7, No. 1, 1996, pp. 23-35.

[3] United Nations Environment Programme (UNEP), "Chemicals: Global Mercury Assessment 1,” April 2002.

[4] G. Chin, J. Chong, A. Kluczewska, A. Lau, J. Gorjy and M. Tennant, "The Environmental Effect of Dental Amalgam,” Australian Dental Journal, Vol. 45, No. 4, December 2000, pp. 246-249.

[5] B. M. Eley, “The Future of Dental Amalgam: A Review of the Literature-Part 2: Mercury Exposure in Dental Practice,” British Dental Journal, Vol. 182, No. 8, April 1997, pp. 293-307.
[6] A. O. Adegbembo, P. A. Watson and S. J. Lugowski, "The Weight of Wastes Generated by Removal of Dental Amalgam Restorations and the Concentration of Mercury in Dental Wastewater," Journal of Canadian Dental Association, Vol. 68, No. 9, October 2002, pp. 553-558.

[7] EIP Associates, “Technical Memorandum Mercury Source Identification Update: Dental Offices and Human Waste," Prepared for the Palo Alto Regional Water Quality Control Plant, 2 March 1999.

[8] P. L. Fan, H. Batchu, H. N. Chou, W. Gasparac, J. Sandrik and D. M. Meyer, "Laboratory Evaluation of Amalgam Separators," Journal of the American Dental Association, Vol. 133, No. 5, May 2002, pp. 577-584.

[9] J. R. Makert, Jr. and M. J. Wahl, “Are There Acceptable Alternatives to Amalgam?” Journal of the California Dental Association, Vol. 32, No. 7, July 2004, pp. 601610.

[10] J. E. Dodes, "The Amalgam Controversy: An EvidenceBased Analysis," Journal of the American Dental Association, Vol. 132, No. 3, March 2001, pp. 348-356.

[11] Northern Virginia Planning District Commission, "Northern Virginia Mercury Reduction Project: Exploring opportunities to reduce mercury discharges from dental offices,” Annandale, Virginia: Northern Virginia Planning District Commission, 1999.

[12] Municipality of Metropolitan Seattle, "Dental Office Waste Stream Characterization Study,” Municipality of Metropolitan Seattle, Seattle, 1991.

[13] S. Gail, "Mercury in Waste Dental Amalgam: Why is it Still a Problem? Local Hazardous Waste Management Program in King County,” December 2003. http://www. gov-link.org/hazwaste/publications/WasteAmalgamProbl ems_03.pdf

[14] P. Watson, A. Adegbembo and S. Lugowski, “A Study of the Fate of Mercury from the Placement and Removal of Dental Amalgam Restorations Final Report Part 1: Removal of Dental Amalgam Restorations," 5 March 2002.

[15] D. Arenholt-Bindslev, "Dental Amalgam-Environmental Aspects," Advances in Dental Research, Vol. 6, No. 1, 1992, pp. 125-130.

[16] Larry Walker Associates, "Mercury source control \& pollution prevention program evaluation: Final report. Association of Metropolitan Sewerage Agencies,” 2002. http://www.oracwa.org/Pages/sources_of_mercury-walke r_report.pdf

[17] D. B. MacDonald, J. F. Fitzgerald and K. McManus, "Mercury in Dental Facilities," Massachusetts Water Resources Authorities Sewerage Division Toxic Reduction and Control Department, Massachusetts, 1997.

[18] O’Connor, Associates Environmental Inc. "Mass Balance of Dental Related Mercury Wastes in Canada,” Environment Canada, 2000.

[19] C. C. Doiron and Associates, "Final Report: Inventory of uses and Releases of Mercury During Product Life Cycles,” Charles E Napier Co. Ltd., Environment Canada ARET Secretariat Ontario, 1998.

[20] A. Adegbembo and P. Watson, "Estimated Quantity of 
Mercury in Amalgam Waste Water Residue Released by Dentists into the Sewerage System in Ontario, Canada," Journal of the Canadian Dental Association, Vol. 70, No. 11, December 2004, pp. 759a-759f.

[21] J. G. Singh, “A Study of Heavy Metals and Hydrocarbons Found in Trinidad," University of the West Indies St.
Augustine, 1989.

[22] L. L. Rojas De Astudillo, "Chemical Investigations on Oysters and Green Mussels from Trinidad and Venezuela," University of the West Indies, St. Augustine, 2002. 